\title{
A IMPORTÂNCIA DA VIVÊNCIA PRÁTICA COMO LIGANTE NO SETOR DE CARDIORRESPIRATÓRIA: UM ESTUDO OBSERVACIONAL
}

\author{
THE RELEVANCE OF PRACTICAL EXPERIENCE AS A MEMBER OF AN ACADEMIC LEAGUE IN \\ THE CARDIORESPIRATORY'S DEPARTMENT: AN OBSERVATIONAL STUDY
}

\section{Júlia Gonçalves Souza, Thalita Leite Oliveira, Victor Hugo Filgueiras da Silva, Ana Carla Calixto Oliveira e Francisca Alana de Lima Santos}

Centro Universitário Doutor Leão Sampaio

\section{RESUMO}

As ligas acadêmicas têm o objetivo de proporcionar atividades extracurriculares a acadêmicos que tem uma área de interesse em comum, instigando o desenvolvimento de ações externas, incentivo a elaboração de estudos científicos e promoção de aulas que direcionam melhor o conhecimento sobre o tema escolhido. Essa pesquisa objetiva demonstrar a importância da participação dos ligantes nas atividades práticas proporcionadas pelas ligas acadêmicas. Trata-se de um estudo observacional descritivo, baseado na experiência prática proporcionada pela Liga Acadêmica de Fisioterapia Respiratória e Cardiovascular, no setor de reabilitação cardiorrespiratória de uma Clínica Escola de Fisioterapia, para acompanhamento de pacientes com diversos quadros clínicos ao longo das semanas. O convite para visitar o setor veio por meio de umas das professoras coordenadoras da LAFIRC. O acompanhamento teve início no dia 20 de agosto de 2021, e seguiu por todas as sextas-feiras subsequentes das $14 \mathrm{~h}$ às $17 \mathrm{~h}$. Iniciamos apenas observando e realizando aferição de sinais vitais enquanto os estagiários do ciclo atual realizavam as condutas terapêuticas. Ao longo das semanas, passamos a realizar condutas da fisioterapia respiratória e em seguida aprendemos a realizar alguns procedimentos cardiofuncionais sempre sob supervisão do preceptor de estágio. Tivemos a oportunidade de acompanhar pacientes hipertensos, diabéticos, hipocalemicos, bronquíticos, arrítmicos, dentre outras patologias frequentes no setor, inclusive pacientes com síndrome pós-covid. Destarte, é possível inferir a relevância da oferta de atividades práticas para os discentes ligantes, para que, com estas, refinem seu raciocínio clínico, conferindo mais segurança nos atendimentos vindouros.

Palavras-chave: Ligas Acadêmicas; Cardiorrespiratória; Prática.

\section{ABSTRACT}

The Academic Leagues provides extracurricular activities for academics with an area of common interest, inciting students to develop outside actions, encourages the construction of scientific studies and promote classes more directed about the theme chosen. The aim of this paper is demonstrate the importance of league members' participation in the practical activities provided. It is about a observational study descriptive based on practical experience, offered by the Respiratory and Cardiovascular Physiotherapy's Academic League, in the department of Cardiorespiratory Rehabilitation from a physiotherapy's school clinic, wherein was possible go along and treat patients with diverse clinical features during the weeks. The invite to visit the department came by one of the coordinators from LAFIRC. The follow-up of the attendance began at 08/20/2021, and continued all the Fridays subsequent from $2 \mathrm{pm}$ to $5 \mathrm{pm}$. We started observing and taking vital signs while the intern from the actual cycle did the therapeutic conducts. Over the weeks, we started to perform some respiratory physiotherapy procedures and after this, we learned some cardio functional procedures always under supervision of the intern's preceptor. We had the opportunity to monitor various clinical conditions as hypertensive, diabetic, hypokalemic, bronchial, arrhythmic patients, among other common pathologies, including patients with post-covid syndrome. Therefore, it is possible to infer the importance offer of practical activities for students from leagues, so that they have contact with the patients and with the techniques refining their clinical reasoning and being more confident during the attendance forthcoming.

Keyword: Academic Leagues; Cardiorespiratory; Practical. 


\section{V.10 N.1 (2022) ISSN: 2317-434X}

\section{INTRODUÇÃO}

A busca por metodologias que melhorem o aprendizado dos educandos é o propósito de professores do mundo todo. Seja com o auxílio de estratégias diferentes ou com o uso de metodologias ativas de aprendizagem, os docentes objetivam incitar o processo de ensino-aprendizagem, estimulando o aluno a assumir o papel de instituidor de seu conhecimento e não somente receptor de informações, como há muito tempo o ensino tradicional preconiza (MELLO et al, 2015). Nesse contexto, a extensão universitária desempenha o papel de potencializar essa relação por meio da diversificação de cenários e metodologias de aprendizagem (FADEL et al, 2013). Tendo em vista que os programas de extensão no ambiente universitário são um método acadêmico junto à sociedade que proporciona um processo educacional, científico e cultural (SILVA et al, 2013).

A extensão pode ser realizada de diferentes formas e, são oferecidas e incentivadas pelas próprias universidades. Dentre elas temos: programas de monitorias, iniciações científicas, o ENACTUS e as ligas acadêmicas. Essas, por sua vez, têm o objetivo de proporcionar atividades extracurriculares a um grupo de acadêmicos que possuem uma área de interesse em comum. Nesse sentido, a vivência extensionista revela-se fundamental na formação universitária, propiciando experiências ampliadas aos graduandos, muito além daquelas obtidas nos moldes tradicionais e bancários de formação profissional (BISCARDE et al, 2014).

Baseadas em pilares de extensão, ensino e pesquisa, as ligas acadêmicas instigam os alunos a desenvolver ações externas (tanto dentro do espaço universitário quanto para a população geral), incentiva a construção de estudos científicos e promove aulas que direcionam melhor o conhecimento sobre o tema escolhido. Dentro dos cursos da área da saúde, em especial na fisioterapia, as atividades práticas oferecidas pelas ligas, trazem o educando para a vivência real do atendimento fisioterapêutico e contato direto com os pacientes.

A imersão do estudante no cotidiano da atenção à saúde traz ricas possibilidades para o aprendizado do cuidado, da organização dos processos de trabalho e da gestão (BISCARDE et al, 2014) pois quando colocados em um ambiente de atendimento real, os estudantes se tornam mais receptivos às informações passadas por seus professores e até mesmo por seus colegas mais experientes, pois, para que haja aprendizagem significativa, são necessárias duas condições: disposição para aprender e que o conteúdo exposto seja significativo para o aprendiz (MELLO et al, 2015), o que vem a ser relevante para o desenvolvimento acadêmico, profissional e pessoal dos membros ligantes, que se tornam estudantes mais proativos, experientes e seguros da escolha de qual especialidade seguir.

Em vista dos termos já abordados, essa pesquisa tem por objetivo demonstrar a importância da participação dos ligantes nas atividades práticas proporcionadas pelas ligas acadêmicas.

\section{METODOLOGIA}

Trata-se, portanto, de um estudo observacional descritivo, baseado na experiência prática, proporcionada pela Liga Acadêmica de Fisioterapia Respiratória e Cardiovascular - LAFIRC, aos seus alunos ligantes, no setor de reabilitação cardiorrespiratória da Clínica Escola de Fisioterapia, do Centro Universitário Dr. Leão Sampaio, na cidade de Juazeiro do Norte, no estado do Ceará. Durante os acompanhamentos dos atendimentos no setor, foi possível monitorar e tratar pacientes com diversos quadros clínicos ao longo das semanas.

O acompanhamento aos atendimentos teve início no dia 20 de agosto de 2021, e seguiu por todas as sextasfeiras subsequentes das $14 \mathrm{hs}$ às $17 \mathrm{hs}$. Estes estão previstos a acontecerem até o final de 2021.

\section{DISCUSSÃO}

A LAFIRC é uma liga acadêmica que se debruça sobre o estudo da fisioterapia cardiovascular, respiratória e terapia intensiva. Buscando sempre trazer os ligantes para uma vivência mais aprofundada dessa área de atuação fisioterapêutica, fomos convidados a visitar o departamento de reabilitação cardiorrespiratória da clínica escola. O convite para visitar o setor veio por meio de uma das professoras coordenadoras da liga. Os 14 ligantes foram divididos em duplas para que não houvesse aglomeração, tendo em vista que estaríamos em contato com os pacientes e com os alunos que estavam passando pelo ciclo de estágio e, cada dupla ficou designada para acompanhamento de um dia da semana, cabendo a esta autora as tardes de sexta-feira.

Antes do início dos atendimentos são feitos debates sobre conceitos ou revisão de algumas condutas úteis aos estagiários para os atendimentos do dia, o que acaba tornando-se um momento importante para que os alunos ligantes possam sanar suas dúvidas também. Depois disso, seguindo o regulamento sanitário da instituição, intensificado durante o período pandêmico, os alunos se encaminham para a sala de paramentação para colocação dos Equipamentos de Proteção Individual (EPIs), jaleco descartável, luvas, toucas, face shield, 


\section{V.10 N.1 (2022) ISSN: 2317-434X}

higienização das mãos e aparelhos eletrônicos para evitar contaminação. Toda a paramentação deve ser trocada após $o$ atendimento, em especial, de pacientes secretivos ou que necessitem retirar a máscara por quaisquer motivos, buscando o menor risco de proliferação viral.

Voltando para a sala de atendimentos, o supervisor do estágio passa o caso do paciente que os ligantes irão acompanhar no dia. Nesse momento é possível conhecer mais sobre as especificidades da patologia em questão e se inteirar sobre as condutas que estão sendo realizadas até então. Nesse sentido, há acesso à ficha de avaliação e as fichas de evolução dos pacientes, o que possibilita uma visão mais ampla sobre o quadro clínico e é indispensável para que tenhamos familiaridade com os prontuários.

Nos primeiros dias, os ligantes apenas observam e realizam aferição de sinais vitais enquanto os estagiários do ciclo atual realizavam as condutas terapêuticas, não sendo raro a elaboração das evoluções do dia, tendo em vista que acompanham todo o atendimento e monitoram o paciente do começo ao fim das condutas. Ao longo das semanas passam a realizar condutas da fisioterapia respiratória baseadas nos 3 pilares de tratamento: desobstrução, expansão e fortalecimento. Dentre as técnicas mais utilizadas no setor tem-se: EPAP carga linear para desobstrução e expansão, EPAP selo d'agua, Voldine, RPPI (Respiração por Pressão Positiva Intermitente), AFE (Aumento de Fluxo Expiratório), PVS (Padrão Ventilatório Seletivo), drenagem postural, acapella e oxigenoterapia.

Em seguida os ligantes são estimulados a realizar alguns procedimentos da fisioterapia cardiofuncional, sempre sob supervisão do supervisor de estágio, tendo em vista que nem todos os membros da LAFIRC haviam passado pelas disciplinas padrão. Nesse sentido, nota-se o ganho de experiência e conhecimento ofertados aos ligantes, que podem antecipar esse conteúdo (ainda que de forma mais direcionada a necessidade do paciente em questão) em relação aos estudantes do mesmo período que não tiveram o mesmo benefício. Dentre os recursos mais utilizados estão: exercícios com bola, bastões e elásticos para membros superiores; exercício na esteira e circuitos voltados ao condicionamento cardíaco.

Dessa forma, houve a oportunidade de acompanhar de pacientes hipertensos, diabéticos, hipocalemicos, bronquíticos, arrítmicos dentre outras patologias frequentes no setor, inclusive pacientes com síndrome pós-covid, o que permitiu conhecer as condutas mais adequadas para cada fisiopatologia e aplicar os conhecimentos que havíamos visto na teoria em pacientes reais o que indubitavelmente contribui para o desenvolvimento do raciocínio clínico, do trato com o paciente e no processo de aprendizado e fixação do conteúdo.

\section{CONCLUSÃO}

Destarte, tendo em vista a necessidade de atualização dos modelos de ensino e aprendizagem, é possível inferir a relevância e necessidade da oferta de atividades práticas para os discentes ligantes por meio dos programas de extensão universitária, para que tenham uma experiência real e um contato próximo com os pacientes e com as técnicas de sua especialidade de interesse para que possam refinar seu raciocínio clínico e conferindo mais segurança nos atendimentos vindouros.

\section{REFERÊNCIAS}

BISCARDE, Daniela Gomes dos Santos et al. Formação em saúde, extensão universitária e Sistema Único de Saúde (SUS): conexões necessárias entre conhecimento e intervenção centradas na realidade e repercussões no processo formativo. 2014. 10 f. Dissertação (Mestrado) Curso de Enfermagem, Universidade Federal da Bahia, Salvador, 2014. Cap. 18.

FADEL, Cristina Berger et al. O impacto da extensão universitária sobre a formação acadêmica em Odontologia. 2013. 17 v. Dissertação (Mestrado) - Curso de Odontologia, Departamento de Odontologia, Universidade Estadual de Ponta Grossa, Ponta Grossa, 2013.
MELLO, Carolina de Castro Barbosa et al. METODOLOGIAS DE ENSINO E FORMAÇÃO NA ÁREA DA SAÚDE: revisão de literatura. 2014. $14 \mathrm{f}$. TCC (Doutorado) - Curso de Fonoaudiologia, Universidade Federal de Minas Gerais, Belo Horizonte, 2014.

SILVA, Thainara Oliveira et al. A IMPORTÂNCIA DA EXTENSÃO UNIVERSITÁRIA NA FORMAÇÃO ACADÊMICA. 2013. 3 f. TCC (Graduação) - Curso de Farmácia, Departamento de Ciências Farmacêuticas, Universidade Federal da Paraiba, Campina Grande, 2013. 